\title{
The energy expenditure of Royal Navy submariners
}

\author{
F. Gunner ${ }^{1}$, D. Reece ${ }^{1}$, C. Hambly ${ }^{2}$, J.R. Speakman ${ }^{2}$ and J.L. Fallowfield ${ }^{1}$ \\ ${ }^{1}$ Environmental and Medicine Sciences, The Institute of Naval Medicine, Gosport, Hampshire, UK, PO12 2DL and \\ ${ }^{2}$ School of Biological Sciences, University of Aberdeen, Aberdeen, Scotland, AB24 2 TZ.
}

Royal Navy (RN) submariners undertake bespoke maritime operational activity confined within an isolated sealed environment. Due to the covert nature of submarine activity, little is known of the physical activity levels and energy expenditure of this type of occupation. From the constraints of the work environment, it would be expected that submariners would have a sedentary to light activity level during patrols. Previous research based on self-reported data indicated Daily Estimated Energy Expenditure (DEEE) to be $13862 \pm 2418 \mathrm{~kJ}$ in Indian submariners ${ }^{(1)}$ whereas a recent Royal Netherlands Navy study reported DEEE of $11167 \pm 2343 \mathrm{~kJ}$ using the doubly labelled water (DLW) technique. ${ }^{(2)}$ The present study aimed to provide information on DEEE of RN personnel undertaking operational submarine activities.

Volunteers $(n=19)$ were recruited from an operationally deployed Trafalgar class RN submarine (Mean \pm SD; Age: $31 \pm 7$ y; Height: $1.78 \pm 0.08$ m; Body Mass: $90.1 \pm 15.7 \mathrm{~kg}$; BMI: $28.3 \pm 3.7 \mathrm{~kg} \cdot \mathrm{m}^{2}$ ). Daily energy expenditure (DEEE, kJ/day) over a routine submerged transit was estimated using the DLW technique ${ }^{(3)}$ and daily Physical Activity was self-monitored using a maritime-specific bespoke task analysis questionnaire (TAQ) over consecutive 10-11 days. The study was approved by the Ministry of Defence Research Ethics Committee (Ref: 0903/228) and volunteers provided informed consent.

Mean estimated energy expenditure calculated from the DLW technique was $12800 \pm 1700 \mathrm{~kJ}(3078 \pm 413 \mathrm{kcal})$, whereas derived from analysis of the TAQ it was $13004 \pm 1594 \mathrm{~kJ}(3108 \pm 381 \mathrm{kcal})$ (Figure 1). There was no correlation between DEEE obtained from the two methods $(\mathrm{r}=0.253, \mathrm{P}=0.296)$. The mean difference between the two techniques (DLW vs. TAQ) was $-127 \pm 2032 \mathrm{~kJ}(\mathrm{LoA}$ : -4107 to $3853 \mathrm{~kJ})$.

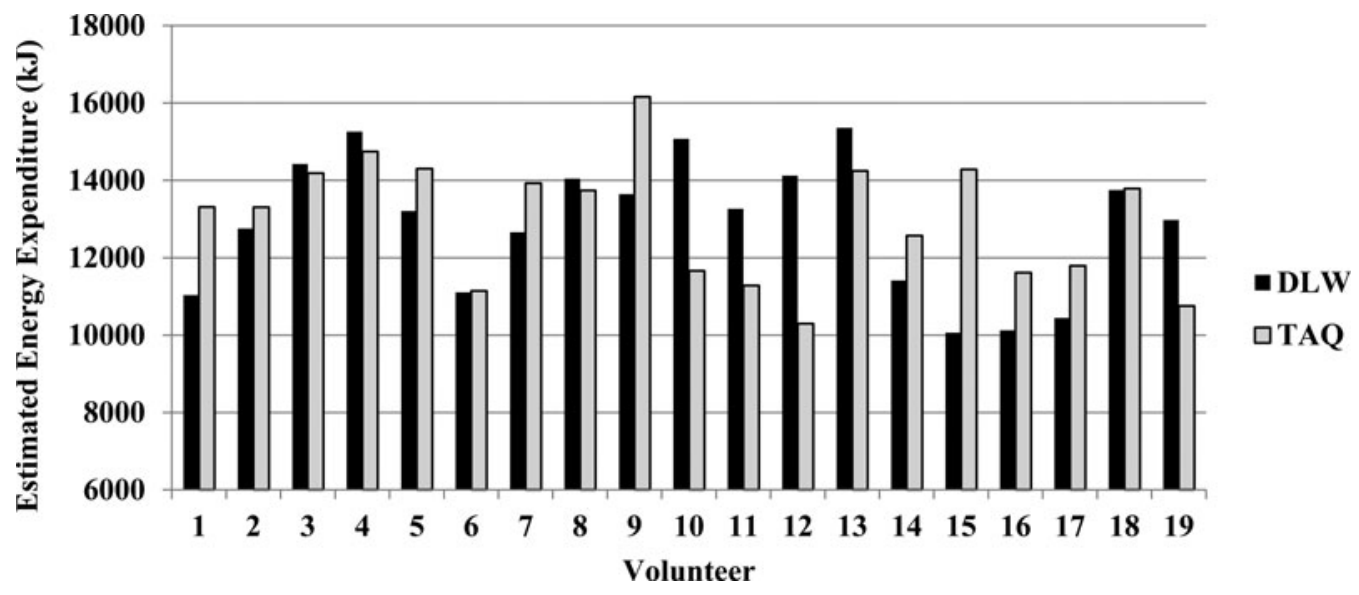

Fig. 1. Individual Estimated Energy Expenditure of RN Submariners $(n=19)$.

In conclusion, the energy expenditure of RN submariners, as measured by the gold standard DLW technique, was comparable to previously published data in similar military cohorts. Self-reported task analysis appears to be a poor descriptor of DEE due to being highly variable between individuals and not correlated to a more robust method. However, the utility of bespoke task analyses could be improved by the development of maritime military-specific physical activity level reference values instead of applying generic tasks.

1. Singh VK et al. (2011) Def Sci Jl 61(6), 540-544.

2. Helmhout P et al. (2017) J Sci Med Sport 20, S111.

3 . Lifson \& McClintock (1966) J Theo Bio 12, 46-74.

(C) Crown Copyright (MOD) 2013: Published with the permission of the Controller of HMSO. 